\title{
Estrogen Receptor Alpha (ESR-1) Associations with Psychological Traits in Women with PMDD and Controls
}

\author{
Alexandra Miller ${ }^{*}, \mathrm{a}$, Hoa Vo $^{*}, \mathrm{~b}$, Liang Huo ${ }^{\mathrm{c}, \mathrm{d}}$, Catherine Rocac ${ }^{\mathrm{C}}$, Peter J. Schmidt ${ }^{\mathrm{C}}$, and David \\ R. Rubinowa,c
}

${ }^{\text {aDepartment }}$ of Psychiatry, University of North Carolina at Chapel Hill; Chapel Hill, North Carolina bVeterans Affairs Hospital; Honolulu, Hawaii cBehavioral Endocrinology Branch, NIMH, NIH; Bethesda, Maryland dSynergy America, Inc; Gaithersburg, Maryland

\begin{abstract}
Premenstrual Dysphoric Disorder (PMDD) is a mood disorder affecting about 5\% of women and is associated with substantial morbidity. Albeit inconsistently, PMDD is described as being characterized by heritable personality traits. Although PMDD is a heritable disorder, it is unclear whether any of the heritable susceptibility to PMDD resides in heritable personality traits. In groups of carefully characterized women with PMDD $(n=68)$ and controls $(n=56)$, we attempted to determine whether diagnosis-related traits could be confirmed, as well as to determine whether such traits were associated with SNPs in estrogen receptor alpha (ESR-1) that we previously demonstrated were associated with PMDD. We observed 7/25 traits to be significantly different in patients and controls and further showed that 11/12 significant associations observed between these 7 traits and 16 ESR-1 SNPs involved the intron 4 SNPs previously shown to be the locus of the association with PMDD. While several interactions between genotype and diagnosis were observed, the effect of genotype in most instances was in the same direction in patients and controls. These data demonstrate affective state-independent personality traits that distinguish patients with PMDD from controls and further support the relevance of ESR-1 polymorphic variants in the regulation of non-reproductive behaviors.
\end{abstract}

\section{Keywords}

estrogen receptor; premenstrual dysphoric disorder; TPQ; 16PF; NEO; estradiol; mood

\footnotetext{
C 2010 Elsevier Ltd. All rights reserved.

Corresponding Author:, Dr. David R. Rubinow, MD, University of North Carolina at Chapel Hill, 10514 Neurosciences Hospital, CB 7160, Chapel Hill, NC 27599-7160, 919 966-4738 (phone), 919 966-7659 (fax).

Authors contributed equally to the paper.

Publisher's Disclaimer: This is a PDF file of an unedited manuscript that has been accepted for publication. As a service to our customers we are providing this early version of the manuscript. The manuscript will undergo copyediting, typesetting, and review of the resulting proof before it is published in its final citable form. Please note that during the production process errors may be discovered which could affect the content, and all legal disclaimers that apply to the journal pertain.

Contributors: Alexandra Miller and Hoa Vo analyzed different components of the study and contributed equally to the writing of the manuscript and creating figures. Liang Huo performed all genotyping. Catherine Roca initiated the study and collected blood samples for genotyping. Peter Schmidt managed all patients and controls participating in the study and contributed to manuscript preparation. David Rubinow directed the analysis and interpretation of the data and contributed to manuscript preparation.
} 


\section{Introduction}

Premenstrual Dysphoric Disorder (PMDD) is a disorder of affect dysregulation that affects approximately $4-8 \%$ of women of reproductive age and is associated with degrees of morbidity similar to those associated with major depression (Halbreich et al., 2003). Results from several (but not all) (Payne et al., 2009) twin studies suggest that PMDD or, more specifically, premenstrual syndrome (PMS - a diagnosis predating PMDD consisting of mood and/or somatic symptoms confined to the luteal phase) is heritable, as are non-syndromal premenstrual affective symptoms (Kendler et al., 1992); (Treloar et al., 2002); (Condon, 1993). Further, in a previous study, we identified an association between PMDD and four intronic polymorphisms in the estrogen receptor alpha (ESR-1) gene (Huo et al., 2007). Although the contribution of specific genes to the variation in disorders like PMDD is likely to be small, many studies suggest that the "deconstruction" of psychiatric illnesses into their symptomatic components may identify endophenotypes that more clearly reflect the effects of common structural genetic variants that contribute to the susceptibility to these disorders (Chan \& Gottesman, 2008). Indeed, several psychometric instruments (e.g. the Tridimensional Personality Questionnaire (TPQ), which is described in the methods section) have been shown to identify factors that are ostensibly heritable and likely to reflect genetic variance (Heath et al., 1994); (Zohar et al., 2003). Thus, these tools may advance our efforts to identify the genetic contributions to behavioral disorders.

Efforts to identify personality traits and personality disorders that are disproportionately common among women with PMDD have yielded inconsistent results, perhaps consequent to methodological confounds such as small sample sizes, lack of matched, healthy controls, and presumptions that state-related symptoms were traits (Verri et al., 1997); (Freeman et al., 1995); (Williams et al., 2007). Freeman et al. (1995) demonstrated elevated scores on all three personality dimensions of the TPQ, particularly Harm Avoidance and Novelty Seeking, in women with PMS compared with normative sample data; however, only 22\% of PMS subjects had high scores in more than one dimension, which suggests that no single pattern was strongly characteristic of PMS subjects. Another study employing the TPQ and comparing PMDD subjects with healthy controls found higher Harm Avoidance scores in the PMDD sample (Verri et al., 1997). Other studies have also linked traits such as Neuroticism, Harm Avoidance, and Novelty Seeking to women suffering from premenstrual mood disorders (e.g., PMS) (Berlin et al., 2001); (Coppen \& Kessel, 1963); (Freeman et al., 1995); (Taylor, 1979); (Gath et al., 1987). As measured by the Personality Diagnostic Questionnaire-Revised (PDQ-R), the "likelihood" or "possibility" of having a personality disorder was found to be significantly higher in women with PMDD compared with asymptomatic controls in both the follicular and luteal phases (thus implying trait rather than state-dependent differences) (Berlin et al., 2001). Nonetheless, on several subscales, a diagnosis by phase interaction was found showing a luteal phase-dependent increase in scores in PMDD subjects but not in asymptomatic controls (Berlin et al., 2001).

Previous studies of heritability and genetic association have uncovered genetic links to PMDD. The initial indication of heritability came not from studies of the syndrome PMDD or PMS but rather from studies comparing the premenstrual symptoms of mothers and daughters and those of monozygotic (MZ) vs. dizygotic (DZ) twins (Condon, 1993); (Kendler et al., 1992); (Wilson et al., 1991). Wilson and colleagues found that daughters of mothers with self-reported PMS were more likely to experience premenstrual symptoms than daughters of mothers without PMS (1991). Two twin studies both found that correlations for MZ twins exceeded those for DZ twins on most PMS subscale items (Condon, 1993); (Kendler et al., 1992). Estimates of heritability for premenstrual symptoms range from $22 \%-37 \%$ and are as high as $43.3 \%$ for severe premenstrual symptoms (Kendler et al., 1992). Several genetic polymorphisms have been tested for possible association with PMDD (Damberg et al., 2005); 
(Melke et al., 2003) including the following: three variants in the serotonin transporter (SLC6A4), specifically the serotonin transporter gene-linked polymorphic region (5HTTLPR) (Heils et al., 1995), an intron 2 variable number of tandem repeats (VNTR) (Ogilvie et al., 1996), and a G to T single nucleotide polymorphism (SNP) in the 3' untranslated region (UTR) (Battersby et al., 1999); an intron 2 VNTR in the gene for transcription factor activating protein 2beta (AP-2beta) (Damberg et al., 2005); gene-based haplotypic variants in genes for estrogen receptor alpha (ESR-1), estrogen receptor beta, and progesterone receptor (Huo et al., 2007). We have previously reported a significant association between PMDD and ESR-1 (Huo et al., 2007); significant associations have also been reported for serotonin receptor 1A (Dhingra et al., 2007) and 5-HTTLPR (Praschak-Rieder et al., 2002).

Although both the heritability of PMDD and its association with personality traits have been investigated, prior studies have not examined the relationship between genotypic variations and personality traits in women with PMDD. As noted above, such studies might reveal genetic influences in PMDD that are more closely expressed in component traits of the disorder. Studies of associations between genetic variants and personality traits have been performed in nonpatient samples. For example, associations were reported between CYP2C19 and CYP2D6 polymorphisms and Harm Avoidance (Ishii et al., 2007); (Roberts et al., 2004). Additionally, studies of genetic association with personality traits have been performed in affective disorders other than PMDD. Findings include associations between Novelty Seeking, Harm Avoidance, Self-Directedness and the T102C polymorphism of the $5-\mathrm{HT}_{2 \mathrm{~A}}$ gene in women with social anxiety disorder (SAD) (Lochner et al., 2007). Based on the previous research and the areas where further study was necessary, we asked the following questions: 1) Can we identify personality "traits" that differ in women with PMDD and controls? 2) Are these "traits" associated with the SNPs in the estrogen receptor alpha gene (ESR-1) that we previously identified as associated with PMDD? 3) Does the genetic variance in ESR-1 influence the variance in the traits similarly in PMDD patients and controls?

\section{Methods and Materials}

\section{Subjects and Recruitment Procedures}

Our sample consisted of 68 women with PMDD and 56 normal, asymptomatic volunteers. Women were recruited through newspaper advertisements. All participants were medicationfree. Women in both groups were similar in socioeconomic status and demographic characteristics (years of education $=17.1+/-3.26$ vs. $16.0+/-2.03$ in controls and patients, respectively, $\mathrm{t}=1.56, \mathrm{p}=\mathrm{ns})$. Prior to entering the study, prospective ratings were employed using a daily visual analogue scale of self-ratings of affective symptoms (Rubinow et al., 1984). Women in the PMDD group had to show at least a $30 \%$ increase in symptoms during the luteal phase, adjusted for the range of the scale employed, for at least two of the three cycles (Smith et al., 2003). All participants additionally met DSM-IV criteria for PMDD (Diagnostic and Statistical Manual of Mental Disorders). Prospective ratings confirmed that women in the control group showed no mood changes related to menstrual cycle phase. All subjects were also administered a Structured Clinical Interview for DSM-IV (SCID) (Spitzer et al., 1990) and a modified Schedule for Affective Disorders and Schizophrenia Lifetime (SADS-L) (Spitzer \& Endicott, 1979); women with PMDD were required to have no current or recent $(<2$ years) Axis I condition, and control women without PMDD were required to have no histories of Axis I disorders. The two-year requirement eliminated subjects with PMDD with significant current or recent comorbidities, which could serve as confounds, but did not eliminate the majority of subjects with PMDD with more remote histories of an Axis I condition. All subjects provided written informed consent, and the protocol was approved by the National Institute of Mental Health Institutional Review Board. All subjects reported regular menstrual cycle lengths, ranging between 21 to 33 days, and none had any significant medical illness within 
the previous year. Although all of the PMDD patients completed questionnaires in the follicular phase, the controls did so in either the follicular or the luteal phase. In order to minimize genetic variation, only Caucasian subjects were used for this analysis. Of the original sample, 40 PMDD and 33 control subjects had both personality and genetic data and were used in the association analysis.

\section{Genotyping}

Genomic DNA was extracted from peripheral lymphocytes obtained from 20-ml of whole blood with the Puregene DNA isolation kit (Gentra Systems, Minneapolis, Minnesota), used according to the manufacturer's instructions. Genotyping was performed by first amplifying genomic DNA by PCR and then reading fluorescence intensity using the Prism 7900HT.

A total of 24 SNPs were selected from the Celera database and SNP database (dbSNP) (http//www.ncbi.nlm.nih.gov/SNP/) to test for association of PMDD with estrogen receptor alpha (ESR-1). A more detailed description of the analysis can be found in (Huo et al., 2007).

\section{Personality Inventories}

The NEO PI-R (Costa \& McCrae, 1992) is a widely used 240-item, self-report questionnaire that is based on decades of factor analytic research with adult populations and provides a systematic assessment of emotional, interpersonal, experiential, attitudinal, and motivational styles. Respondents are given five response choices for each item, ranging from strongly disagree to strongly agree. There are 48 items for each of the five-factor model domain scales including: Neuroticism, Extraversion, Openness, Agreeableness, and Contentiousness. Internal consistency coefficients have ranged from 0.86 (Agreeableness) to 0.92 (Neuroticism), and seven-year test-retest reliability coefficients ranged from 0.63 to 0.81 (Costa \& McCrae, 1992). Cross-cultural and longitudinal studies have provided extensive empirical support for the validity of the NEO (Costa \& McCrae, 1988); (McCrae \& Costa, 1997); (McCrae et al., 1998).

The Tridimensional Personality Questionnaire (TPQ; (Cloninger et al., 1991)) is a 100-item self-report questionnaire that assesses three personality dimensions -- Novelty Seeking, Reward Dependence, and Harm Avoidance --each with four subscales. The dimensions describe basic patterns of adaptive responses to specific classes of environmental stimuli. Novelty Seeking is a tendency to respond strongly to novelty and cues for rewards that leads to frequent exploration in pursuit of rewards and avoidance of punishment. For example, high Novelty Seeking would reflect impulsiveness and disorderliness rather than reflection and regimentation. Harm Avoidance is a tendency to respond strongly to aversive stimuli that leads to learned inhibition of behavior in order to avoid punishment and novelty. For example, high Harm Avoidance would reflect fear of uncertainty and shyness rather than confidence and gregariousness. Reward Dependence is a tendency to maintain behaviors previously associated with reward or relief of punishment and is proposed to be related to the brain systems involved in behavioral maintenance. For example, high Reward Dependence would reflect sentimentality and attachment rather than insensitiveness and detachment. Harm Avoidance is broadly similar but not identical to other measures of neuroticism (Wetzel et al., 1992) that have been previously associated with PMS (Ussher \& Wilding, 1991); (Taylor et al., 1991); (Hallman et al., 1987). Novelty seeking is similar to but not identical with the social dimension of introversion-extraversion (Cloninger et al., 1991) or sensation seeking (McCourt et al., 1993). The TPQ has been reported to be a valid and reliable measure based on normative data from a United States national probability sample of 1019 adults (Cloninger et al., 1991). Alpha coefficients for the TPQ scales in the female sample range from 0.61 to 0.85 and are consistent across demographic groups; test-retest correlations range from 0.70 to 0.79 (Cloninger et al., 1991). 
The 16-Personality Factors (16PF) is designed to measure normal personality traits and has been widely used for more than 40 years for a variety of applications, including treatment planning and counseling (Cattell, 1988); (Conn \& Rieke, 1994). The questionnaire contains sixteen bipolar scales (called "primary factors") and five global factors. The 16PF was chosen because of its ability to measure sixteen independent dimensions that are associated with personality: Warmth, Reasoning, Emotional Stability, Dominance, Liveliness, RuleConsciousness, Social Boldness, Sensitivity, Vigilance, Abstractedness, Privateness, Apprehension, Openness to Change, Self-Reliance, Perfectionism, and Tension. Additionally, the 16PF includes an Impression Management (IM) index that is used as an item-dependent validity scale. IM, which can detect exaggeration of socially desirable responses, may also serve as an index of the attempt to influences one's image in the eyes of others. The stability coefficients for the personality factors and validity scale range from $r=0.69$ to $r=0.91$ for 2 weeks, with the range of $r=0.56$ to $r=0.82$ for 2 months. The internal consistency of the primary factors and validity scale ranged from [alpha] $=0.66$ to [alpha] $=0.87$ (Conn \& Rieke, 1994).

\section{Statistical Analysis}

Statistical analyses were performed using SPSS (version 16.0, 2008). First, diagnostic group differences on the 25 personality traits evaluated by the three scales were assessed using analysis of variance (ANOVA). A total of seven out of twenty-five traits demonstrated significant differences between controls and patients: Neuroticism, Extraversion, Emotional Stability, Abstractedness, Apprehension, Impression Management, and Harm Avoidance. This analysis was performed using the data from all subjects with personality trait data (68 PMDD subjects, 56 controls). The subjects on whom both personality trait and genetic data were obtained (40 PMDD subjects, 33 controls) were used to determine whether there was an effect of genotype or diagnosis on the seven personality traits identified as distinguishing PMDD subjects from controls. A multivariate General Linear Model (GLM) analysis was performed for each SNP, with genotype and diagnosis as the independent factors and the personality traits as the dependent factors. To ensure adequate numbers in each cell, genotypes containing a minor allele (homozygous and heterozygous) were collapsed and compared with the homozygous major allele genotype. A GLM also was performed to determine whether trait scores differed as a function of menstrual phase in controls to ensure there was no phase difference in personality traits. Another GLM was performed on PMDD subjects comparing the personality scores of those with history of depression and those without to examine possible confounding variables.

\section{Results}

As is consistent with previous research, no differences in personality scores were found between those controls tested in the luteal phase and those tested in the follicular phase (Berlin et al., 2001), thus justifying combining all scores for controls irrespective of phase of testing. Seven of a total of 25 traits (across the three instruments used) demonstrated significant differences between controls and patients: Neuroticism ( $F=21.69, \mathrm{p}<0.001)$, Extraversion $(\mathrm{F}=6.90, \mathrm{p}<0.01)$, Emotional Stability $(\mathrm{F}=21.05, \mathrm{p}<0.001)$, Abstractedness $(\mathrm{F}=7.62, \mathrm{p}<0.01)$, Apprehension $(\mathrm{F}=8.35, \mathrm{p}<0.005)$, Harm Avoidance $(\mathrm{F}=12.04, \mathrm{p}<0.001)$ and Impression Management (in this study used as an index of social desirability). $(\mathrm{F}=8.42, \mathrm{p}<0.005)$. To ensure that these differences did not reflect a past history of depression (exclusionary in controls but not patient subjects), a GLM comparing PMDD subjects with $(n=23)$ and without $(n=45)$ past histories of depression was performed and demonstrated a significant effect for one of the seven traits distinguishing patient subjects and controls (Apprehension $(\mathrm{F}=4.869, \mathrm{p}<0.031)$. 
Among these seven traits, twelve significant associations were observed with six of the sixteen SNPs examined (see Table 1). Eleven of twelve of these associations included intron 4 SNPs of ESR-1.

Genotypic associations revealed the following effects of the presence of a minor allele in patients and controls: lower Emotional Stability (L0058), lower Impression Management (L0058) (higher scores indicate a greater attempt to project a socially desirable image), higher Harm Avoidance (L0026, L0060, L0061), higher Neuroticism (L0026), and higher Abstractedness (L0025, L0026, L0060, L0061, L0055, L0058) (high scores reflect ideaoriented, imaginative thinking while low scores reflect practical and concrete thinking) (F values $4.0-9.0$, p's<0.01-0.05) (See Figure 1).

In addition, diagnosis-by-genotype interaction effects were found for four of the SNPs. In patients but not controls, the presence of the minor allele was associated with the following: decreased Emotional Stability (L0058 and L0025) ( $\mathrm{F}=4.22$, p $<0.05 ; \mathrm{F}=5.17, \mathrm{p}<0.05$, respectively); and increased Neuroticism (L0060, L0023, and L0025) $(\mathrm{F}=4.47, \mathrm{p}<0.05$; $\mathrm{F}=4.16, \mathrm{p}<0.05$; and $\mathrm{F}=4.76, \mathrm{p}<0.05$, respectively) (Figure 2).

\section{Discussion}

We identified seven psychological factors as more prominent in women with PMDD compared with controls. Patients had greater scores on personality factors of Neuroticism, Abstractedness, Apprehension, Harm Avoidance, while normal volunteers scored significantly higher on Extraversion, Emotional Stability, and Impression Management. Notably, these differences occurred despite patients completing the personality inventories in the follicular or asymptomatic phase of the menstrual cycles. The validity of these trait differences is supported by both the substantial sample sizes and, particularly, the careful characterization of the study participants. Our data are consistent with earlier demonstrations of psychological trait scores that distinguish PMDD patients from controls. Consistent with our findings, Ross and colleagues found Neuroticism (NEO) accounted for a significant amount of variation in premenstrual negative affect both before and after controlling for baseline (follicular) symptom levels (2001), and Freeman and colleagues showed that PMS subjects scored significantly higher on Harm Avoidance (as well as on Novelty Seeking and Reward Dependence) (1995). More recently, Payne and colleagues found an association between high Openness (NEO) scores and premenstrual mood symptoms (2009). Our findings similarly identified associations with Neuroticism (NEO) and Harm Avoidance (TPQ) among others. Whether these "trait" differences contribute to or are a consequence of PMDD, it is, nonetheless, clear that they are enduring and not state-dependent (i.e. confined to the luteal phase).

While personality traits in PMDD subjects were assessed in the follicular phase, measures for control subjects were obtained in both the follicular and luteal phases. To ensure that menstrual phase was not a confounding variable, scores from controls taken in the follicular phase were compared with those taken during the luteal phase. No significant differences were found between the two phases. These results confirm the findings of Berlin (2001) that personality traits do not differ with menstrual cycle phase in asymptomatic controls.

Our novel findings are the demonstration of significant associations between five of these personality traits and previously identified polymorphic variants in ESR-1. Huo et al (2007) found that four SNPs in intron 4 of ESR-1 distinguished between PMDD patients and controls (L0025, L0060, L0061, L0026). An additional SNP (L0058) trended toward the separation of patients from controls and was found to be in tight linkage disequilibrium with the other intron 4 SNPs, L0025, L0060, L0061, and L0026 (63\%, 83\%, 84\%, and 74\% respectively). Eleven of the twelve associations that we observed with the psychological factors that distinguished 
PMDD patients from controls involved these intron 4 SNPs. Thus, the SNPs that are associated with traits that are relevant for PMDD almost uniformly cluster in intron 4 of ESR-1. Both the positive finding of associations between psychometric factors and SNPs associated with PMDD, as well as the negative informational value of failure to find SNPs elsewhere in the gene that associate with these psychometric traits, reinforce the results from our previous study indicating the importance of intron 4 SNPs in PMDD.

These findings raise several questions. The first of these questions is whether both PMDD and the traits that we assessed are heritable. Several twin studies strongly suggest that premenstrual symptoms and PMS are heritable, with the heritability for severe premenstrual symptoms estimated as high as 43\% (Kendler et al., 1992); (Treloar et al., 2002); (Condon, 1993).

Additionally, genetic associations have been found between PMDD and polymorphic variants of several genes: ESR-1, serotonin receptor 1A and 5-HTTLPR, the latter in women who also had social anxiety disorder (Huo et al., 2007); (Dhingra et al., 2007); (Praschak-Rieder et al., 2002).

Evidence for the heritability of psychological traits comes from several sources. Kandler and colleagues found NEO personality traits to have higher correlations between MZ twins than DZ twins, which suggests genetic influences (2009). A similar study of the TPQ scale found that all scales of the test showed higher correlations for MZ pairs than for DZ pairs (Heath et al., 1994). Finally, the TPQ trait of Harm Avoidance has a confirmed genetic linkage to locus chromosome 8p21-3 (Cloninger et al., 1991); (Zohar et al., 2003). Thus, these findings together with the diagnosis-related trait differences noted above indicate that these personality traits are not only heritable but also exhibit significant differences between PMDD subjects and controls.

The second question is whether there is a basis for inferring that variation in estrogen receptor signaling would contribute to different psychological properties of PMDD. Multiple observations suggest the potential behavioral regulatory potency of ESR-1. These observations include the following: 1) Estrogen regulates both blood flow and dopamine metabolism in the prefrontal cortex, an area identified as critical in affective regulation (Berman et al., 1997); (Keenan et al., 2001). 2) In rodents, the neurocircuitry that is selected to solve a specific cognitive task varies as a function of estradiol levels (Zurkovsky et al., 2007). 3) In women with PMDD, changes in estradiol levels have been demonstrated to precipitate affective destabilization (Schmidt et al., 1998). Thus, estradiol-mediated signaling appears to play a prominent role in the activation of neurocircuitry relevant to social cognition and affect regulation.

Finally, are the associations we observed random or meaningful? We attempted to decrease the number of associations that would appear significant by chance by interrogating one gene (which we demonstrated as associated with PMDD) and only those psychological factors we observed in a larger sample to distinguish patients and controls. When looking at the seven traits and sixteen SNPs, approximately six associations would be expected to be found by chance when using $\mathrm{p}=0.05$ as a significance level, and these would be expected to have a random distribution across the gene. However, our analysis found twelve significant genetic interactions, and eleven out of twelve of the associations were found in the intron 4 SNPs. These intron 4 SNPs were the same identified as being associated with PMDD or, in the case of one SNP (L0058), in very close linkage disequilibrium with the associated SNPs. It therefore seems unlikely that the significant trait associations that we observed are a product of chance. It is worth noting, nonetheless, that the direction of the main effect of the SNP on the psychological traits was not what we would have predicted from the comparative distribution of major and minor alleles in women with PMDD and controls. In our previous study, the minor alleles were invariably associated with controls and consequently appeared to serve a protective function. Conversely, the minor alleles appear associated with increased symptomatic scores 
in both patients and controls. How might we reconcile the ostensibly contradictory findings that ESR-1 is associated with PMDD and with four traits that characterize PMDD, but not in the predictable direction?

The estrogen receptor alpha gene might influence behavioral expression in women with PMDD in several ways: 1) by contributing to the regulation of behavioral traits that are relevant to PMDD irrespective of diagnosis (i.e., same effect in patients and controls), and 2) by influencing susceptibility to the development of PMDD. Thus, ESR-1 variants may, in concert with other genes and environmental factors, predispose toward expression of certain traits, but also may display epistasis with what are likely to be independent genetic factors to influence the susceptibility toward steroid- regulated affective disorders. These findings indirectly support Kendler's demonstration that personality traits and PMDD are independently heritable (Kendler et al., 1992). Thus, unlike Major Depression, in which much of the heritability may reside in heritable personality (Kendler et al., 1992), PMDD displays heritability that is distinct from the personality traits that may characterize women with this disorder.

A similar explanation could be adduced for the paradoxical interactive effects of diagnosis and genotype on personality traits that we also observed, in which the presence of the minor allele is associated with an increase in Neuroticism and a decrease in Emotional Stability in women with PMDD and not controls. Thus, the effect of the gene differs in the two different populations, a phenomenon reminiscent of the differing behavioral consequences of gene knockout in male and female animals (Krezel et al., 2001). Considerable limitations notwithstanding, these findings lend further support to the idea that reproductive steroids are relevant to behavioral expression in asymptomatic women, as well as in women with reproductive steroid-related mood disorders.

A significant limitation of our study is the small sample size (for genetic association studies). Several steps were taken, however, to decrease the impact of this limitation. First, the sample was diagnostically very well characterized, which decreases clinical heterogeneity. Second, only polymorphisms in a gene already demonstrated to be significantly associated with PMDD were examined. Third, the association analysis was restricted to behavioral traits that had previously been found (in this study) to discriminate between patients and controls. Thus the sample used was a purified sample with a priori reasons for looking at the clinical measures and with both genetic variants and psychological factors that had been previously shown to differ in patients and controls. The limited number of comparisons performed decreased the likelihood that observed associations are the product of chance. Another potential limitation is the association of a history of depression in PMDD patients with the trait of Apprehension; however, this is the only association we found with a history of depression, and Apprehension was not significantly associated with any of the SNPs. Nonetheless, the possibility that these findings would differ if the history of depression were excluded can not be ruled out.

In conclusion, we have identified several personality traits that distinguish PMDD patients from normal controls and that are predominantly associated with intron 4 SNPs in the estrogen receptor alpha gene. These findings, while clearly preliminary, are instructive for several reasons: 1) Genes coding for reproductive steroids, not surprisingly, are promising and potentially potent sources of behavioral variance; 2 ) The decomposition of syndromes into component processes - in this case personality traits - may be a superior strategy for identifying the genetic contributions to affective disorders than examining the syndrome as a unitary structure; 3) If personality traits in PMDD are heritable, then identification of profiles of traits in larger samples might improve the resolution of our efforts to understand the contribution of genetic factors to the susceptibility to experience PMDD. 


\section{Acknowledgments}

The authors gratefully acknowledge the efforts of Karla Thompson, who provided great assistance in data collection and entry.

Funding source: This study was conducted as part of our duties as employees of the federal government and hence is not subject to copyright. Funding for this study was provided under NIH research project \#1 z01 MH002765-09.

\section{References}

Battersby S, Ogilvie AD, Blackwood DHR, Shen S, Muqit MMK, Muir WJ, Teague P, Goodwin GM, Harmar AJ. Presence of multiple functional polyadenylation signals and a single nucleotide polymorphism in the $3^{\prime}$ untranslated region of the human serotonin transporter gene. Journal of Neurochemistry 1999;72:1384-1388. [PubMed: 10098839]

Berlin RE, Raju JD, Schmidt PJ, Adams LF, Rubinow DR. Effects of the menstrual cycle on measures of personality in women with premenstrual syndrome: a preliminary study. Journal of Clinical Psychiatry 2001;62:337-342. [PubMed: 11411814]

Berman KF, Schmidt PJ, Rubinow DR, Danaceau MA, Van Horn JD, Esposito G, Ostrem JL, Weinberger DR. Modulation of cognition-specific cortical activity by gonadal steroids: a positron-emission tomography study in women. Proceedings of the National Academy of Sciences of the United States of America 1997;94:8836-8841. [PubMed: 9238064]

Cattell, R. Handbook for the sixteen personality factor questionnaire (16 PF). Champaign, IL: Institute for Personality and Ability Testing; 1988.

Chan RC, Gottesman II. Neurological soft signs as candidate endophenotypes for schizophrenia: a shooting star or a Northern star? Neuroscience Biobehavior Review 2008;32(5):957-971.

Cloninger CR, Przybeck TR, Svrakic DM. The Tridimensional Personality Questionnaire: U.S. normative data. Psychology Report 1991;69(3 Pt 1):1047-1057.

Condon J. The Premenstrual Syndrome: A Twin Study. British Journal of Psychiatry 1993;162:481-486. [PubMed: 8481739]

Conn, S.; Rieke, M. Construct validation of the 16PF fifth edition. Champaign, IL: Institute for Personality and Ability Testing; 1994.

Coppen A, Kessel N. Menstruation and personality. British Journal of Psychiatry 1963;109:711-721. [PubMed: 14080565]

Costa P, McCrae R. Normal personality assessment in clinical practice: The NEO personality inventory. Psychological Assessment 1992;4(1):5-13.

Costa PT Jr, McCrae RR. Personality in adulthood: a six-year longitudinal study of self-reports and spouse ratings on the NEO personality inventory. Journal of Personality and Social Psychology 1988;54(5): 853-863. [PubMed: 3379583]

Damberg M, Westberg L, Berggard C, Landen M, Sundblad C, Eriksson O, Naessen T, Ekman A, Eriksson E. Investigation of transcription factor AP-2beta genotype in women with premenstrual dysphoric disorder. Neuroscience Letters 2005;377:49-52. [PubMed: 15722186]

Dhingra V, Magnay JL, O'Brien PM, Chapman G, Fryer AA, Ismail KM. Serotonin receptor 1A C(-1019) $\mathrm{G}$ polymorphism associated with premenstrual dysphoric disorder. Obstetrics and Gynecology 2007;110(4):788-792. [PubMed: 17906010]

Diagnostic and Statistical Manual of Mental Disorders. 4th ed. Washington, D.C.: American Psychiatric Association; 1994.

Freeman EW, Schweizer E, Rickels K. Personality factors in women with premenstrual syndrome. Psychosomatic Medicine 1995;57(5):453-459. [PubMed: 8552736]

Gath D, Osborn M, Bungay G, Iles S, Day A, Bond A, Passingham C. Psychiatric disorder and gynaecological symptoms in middle aged women: a community survey. British Medical Journal (Clinical Research Edition) 1987;294(6566):213-218.

Halbreich U, Borenstein J, Pearlstein T, Kahn LS. The prevalence, impairment, impact, and burden of premenstrual dysphoric disorder (PMS/PMDD). Psychoneuroendocrinology 2003;28:1-23. 
Hallman J, Oreland L, Edman G, Schalling D. Thrombocyte monoamine oxidase activity and personality traits in women with severe premenstrual syndrome. Acta Psychiatrica Scandinavica 1987;76(3): 224-234.

Heath AC, Cloninger CR, Martin NG. Testing a model for the genetic structure of personality: a comparison of the personality systems of Cloninger and Eysenck. Journal of Personality and Social Psychology 1994;66(4):762-775. [PubMed: 8189351]

Heils A, Teufel A, Petri S, Seemann M, Bengel D, Balling U, Riederer P, Lesch KP. Functional promoter and polyadenylation site mapping of the human serotonin (5-HT) transporter gene. Journal of Neural Transmission [General Section] 1995;102:247-254.

Huo L, Straub R, Schmidt PJ, Shi K, Vakkalanka R, Weinberger D, Rubinow DR. Risk for premenstrual dysphoric disorder is associated with genetic variation in ESR1, the estrogen receptor alpha gene. Biological Psychiatry 2007;62(8):925-933. [PubMed: 17599809]

Ishii G, Suzuki A, Oshino S, Shiraishi H, Otani K. CYP2C19 polymorphism affects personality traits of Japanese females. Neuroscience Letters 2007;411:77-80. [PubMed: 17052843]

Kandler C, Riemann R, Kampfe N. Genetic and environmental mediation between measures of personality and family environment in twins reared together. Behavior Genetics 2009;39(1):24-35. [PubMed: 19005750]

Keenan PA, Ezzat WH, Ginsburg K, Moore GJ. Prefrontal cortex as the site of estrogen's effect on cognition. Psychoneuroendocrinology 2001;26:577-590. [PubMed: 11403979]

Kendler KS, Silberg JL, Neale MC, Kessler RC, Heath AC, Eaves LJ. Genetic and environmental factors in the aetiology of menstrual, premenstrual and neurotic symptoms: a population-based twin study. Psychological Medicine 1992;22:85-100. [PubMed: 1574568]

Krezel W, Dupont S, Krust A, Chambon P, Chapman P. Increased anxiety and synaptic plasticity in estrogen receptor beta-deficient mice. Proceedings of the National Academy of Sciences of the United States of America 2001;98(21):12278-12282. [PubMed: 11593044]

Lochner C, Hemmings S, Seedat S, Kinnear C, Schoeman R, Annerbrink K, Olsson M, Eriksson E, Moolman-Smook J, Allgulander C, Stein DJ. Genetics and personality traits in patients with social anxiety disorder: a case-control study in South Africa. European Neuropsychopharmacology 2007;17 (5):321-327. [PubMed: 16899354]

McCourt WF, Gurrera RJ, Cutter HS. Sensation seeking and novelty seeking: Are they the same? Journal of Nervous and Mental Disease 1993;181(5):309-312. [PubMed: 8501447]

McCrae RR, Costa PT Jr. Personality trait structure as a human universal. American Psychology 1997;52 (5):509-516.

McCrae RR, Stone SV, Fagan PJ, Costa PT Jr. Identifying causes of disagreement between self-reports and spouse ratings of personality. Journal of Personality 1998;66(3):285-313. [PubMed: 9615420]

Melke J, Westberg L, Landen M, Sundblad C, Eriksson O, Baghei F, Rosmond R, Eriksson E, Ekman A. Serotonin transporter gene polymorphisms and platelet $[3 \mathrm{H}]$ paroxetine binding in premenstrual dysphoria. Psychoneuroendocrinology 2003;28:446-458. [PubMed: 12573307]

Ogilvie AD, Battersby S, Bubb VJ, Fink G, Harmar AJ, Goodwin GM, Dale Smith CA. Polymorphism in serotonin transporter gene associated with susceptibility to major depression. Lancet 1996;347:731-733. [PubMed: 8602004]

Payne JL, Klein SR, Zamioski RB, et al. Premenstrual mood symptoms: Study of familiality and personality correlates in mood disorder. Archives of Women's Mental Health 2009;12(1):27-34.

Praschak-Rieder N, Willeit M, Winkler D, Neumeister A, Hilger E, Zill P, Hornik K, Stastny J, Thierry N, Ackenheil M, Bondy B, Kasper S. Role of family history and 5-HTTLPR polymorphism in female seasonal affective disorder patients with and without premenstrual dysphoric disorder. European Neuropsychopharmacology 2002;12:129-134. [PubMed: 11872329]

Roberts RL, Luty SE, Mulder RT, Joyce PR, Kennedy MA. Association between cytochrome P450 2D6 genotype and harm avoidance. American Journal of Medical Genetics Part B: Neuropsychiatric Genetics 2004;127B(1):90-93.

Ross C, Coleman G, Stajanovska C. Relationship between the NEO personality inventory revised neuroticism scale and prospectively negative affect across the menstrual cycle. Journal of Psychosomative Obstetrics \& Gynecology 2001;22(3):165-176. 
Rubinow DR, Roy-Byrne PP, Hoban MC, Gold PW, Post RM. Prospective assessment of menstrually related mood disorders. American Journal of Psychiatry 1984;141:684-686. [PubMed: 6538762]

Schmidt PJ, Nieman LK, Danaceau MA, Adams LF, Rubinow DR. Differential behavioral effects of gonadal steroids in women with and in those without premenstrual syndrome. New England Journal of Medicine 1998;338:209-216. [PubMed: 9435325]

Smith MJ, Schmidt PJ, Rubinow DR. Operationalizing DSM-IV criterion for PMDD: Selecting symptomatic and asymptomatic cycles for research. Journal of Psychiatry Research 2003;37:75-83.

Spitzer, RL.; Endicott, J. Schedule for affective disorders and schizophrenia - lifetime version. New York, NY: Biometrics Research Department, New York State Psychiatric Institute; 1979.

Spitzer, RL.; Williams, JB.; Gibbon, M.; First, MB. Structured clinical interview for DSM-III-R. patient edition. New York, NY: Biometrics Research Department, New York State Psychiatric Institute; 1990.

Taylor JW. Plasma progesterone, oestradiol 17 beta and premenstrual symptoms. Acta Psychiatrica Scandinavica 1979;60:76-86. [PubMed: 573048]

Taylor R, Fordyce D, Alexander D. Relationship between personality and premenstrual symptoms: a study in five general practices. British Journal of General Practice 1991;41(343):55-57. [PubMed: 2031736]

Treloar SA, Heath AC, Martin NG. Genetic and environmental influences on premenstrual symptoms in an Australian twin sample. Psychological Medicine 2002;32(1):25-38. [PubMed: 11883728]

Ussher JM, Wilding JM. Performance and state changes during the menstrual cycle, conceptualised within a broad band testing framework. Social Science \& Medicine 1991;32(5):525-534. [PubMed: 2017719]

Verri A, Nappi RE, Vallero E, Galli C, Sances G, Martignoni E. Premenstrual dysphoric disorder and eating disorders. Cephalalgia 1997;(17 Suppl 20):25-28. [PubMed: 9496774]

Wetzel RD, Knesevich MA, Brown SL, Wolff HA, Horn CJ Sr, Cloninger CR. Correlates of tridimensional personality questionnaire scales with selected Minnesota multiphasic personality inventory scales. Psychology Report 1992;71(3 Pt 2):1027-1038.

Williams WR, Richards JP, Ameen JR, Davies J. Recurrent brief depression and personality traits in allergy, anxiety and premenstrual syndrome patients: a general practice survey. Medical Science Monitor 2007;13(3):CR118-CR124. [PubMed: 17325634]

Wilson CA, Turner CW, Keye WR Jr. Firstborn adolescent daughters and mothers with and without premenstrual syndrome: a comparison. Journal of Adolescent Health 1991;12(2):130-137. [PubMed: 2015237]

Zohar A, Dina C, Rosolio N, Osher Y, Gritsenko I, Bachner-Melman R, Benjamin J, Belmaker R, Ebstein R. Tridimensional Personality Questionnaire Trait of Harm Avoidance (Anxiety Proneness) is Linked to a Locus on Chromosome 8p21. American Journal of Medical Genetics Part B (Neuropsychiatric Genetics) 2003;117B(1):66-69.

Zurkovsky L, Brown SL, Boyd SE, Fell JA, Korol DL. Estrogen modulates learning in female rats by acting directly at distinct memory systems. Neuroscience 2007;144(1):26-37. [PubMed: 17052857] 


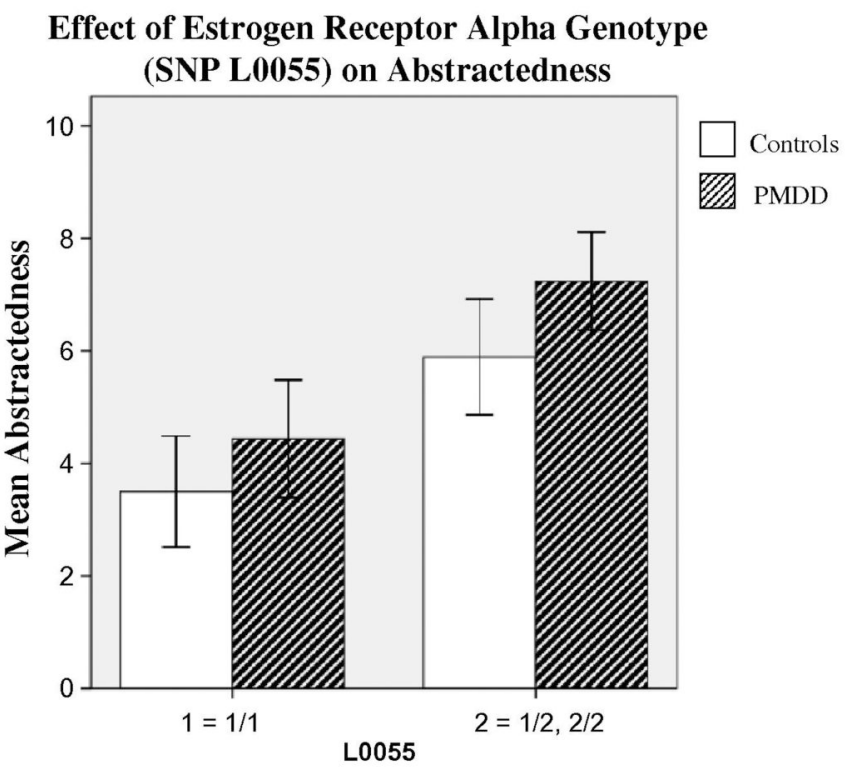

\section{Effect of Estrogen Receptor Alpha Genotype} (SNP L0058) on Impression Management

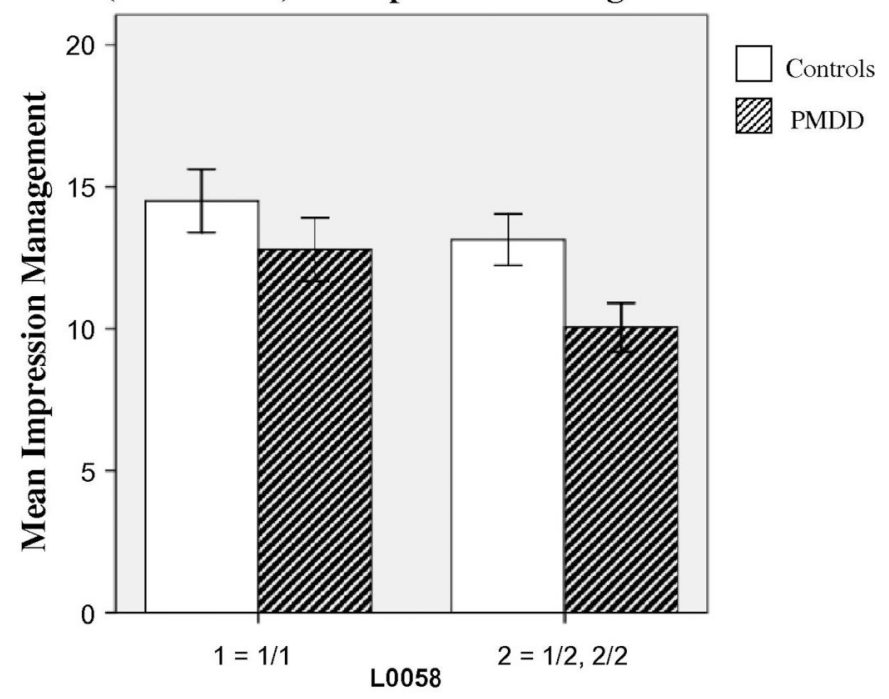

Effect of Estrogen Receptor Alpha Genotype

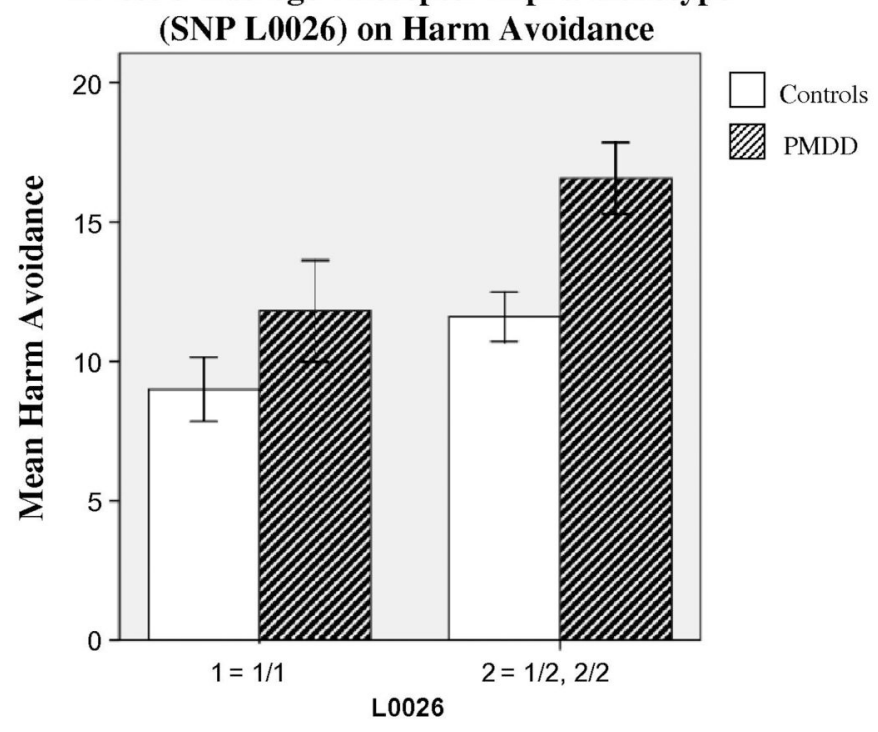

Figure 1.

Error Bar: +/- $1 \mathrm{SE}$

Three sample comparisons of psychological traits in subjects homozygous for the major allele $(1 / 1)$ with those in whom a minor allele was present $(1 / 2,2 / 2)$ in patients with PMDD and controls. Impression Management scores are lower in subjects carrying the minor allele in both the PMDD and control samples (genotypic effect, $\mathrm{F}_{1}=4.04, \mathrm{p}=.05$ ). The opposite effect is seen with Abstractedness and Harm Avoidance (genotypic effects, $\mathrm{F}_{1}=6.82$, $\mathrm{p}=.01$ and $\mathrm{F}_{1}=6.77, \mathrm{p}=$. 01 , respectively). In both samples, the subjects carrying the minor allele have higher scores compared with those homozygous for the major allele in both the PMDD and control samples. 
Interaction Effects of Estrogen Receptor Alpha Genotype (SNP L0025) and Diagnosis on Emotional Stability

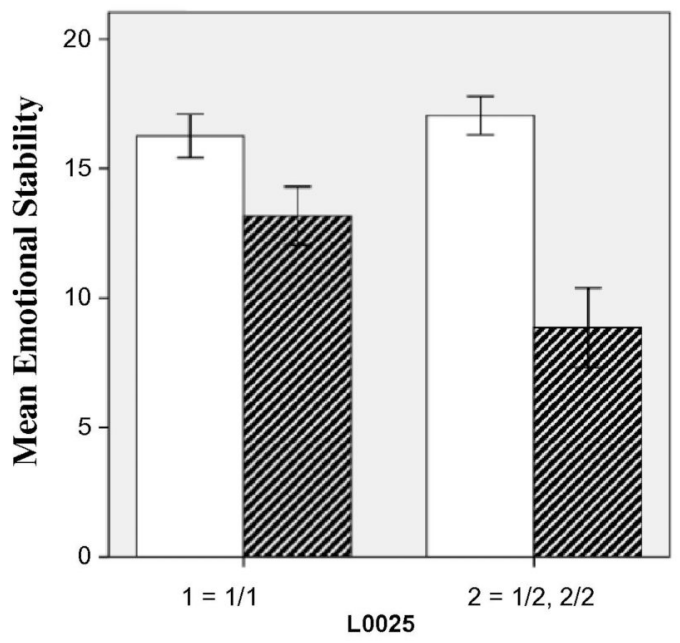

Interaction Effects of Estrogen Receptor Alpha Genotype (SNP L0025) and Diagnosis on Neuroticism

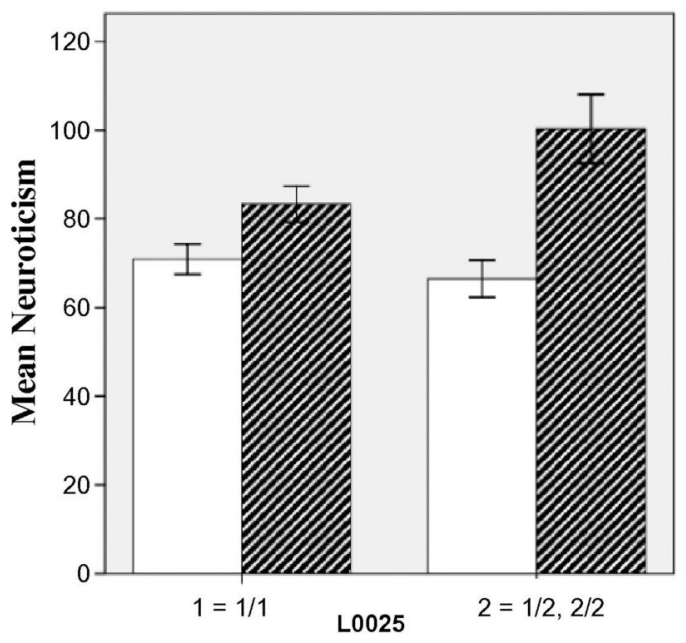

Figure 2.

Error Bar: +/- $1 \mathrm{SE}$

Two representative examples of the interaction effects between genotype and diagnosis (PMDD vs controls) on psychological trait scores.

(A) Although the Emotional Stability scores of the controls do not change with genotype, the PMDD subjects who are carrying the minor allele show decreased Emotional Stability scores $\left(\mathrm{F}_{1}=5.17, \mathrm{p}=.03\right)$.

(B) A similar trend appears with Neuroticism. Control subjects maintain similar scores regardless of allele, while PMDD subjects who carry the minor allele have increased Neuroticism scores $\left(\mathrm{F}_{1}=4.76, \mathrm{p}=.03\right)$. 


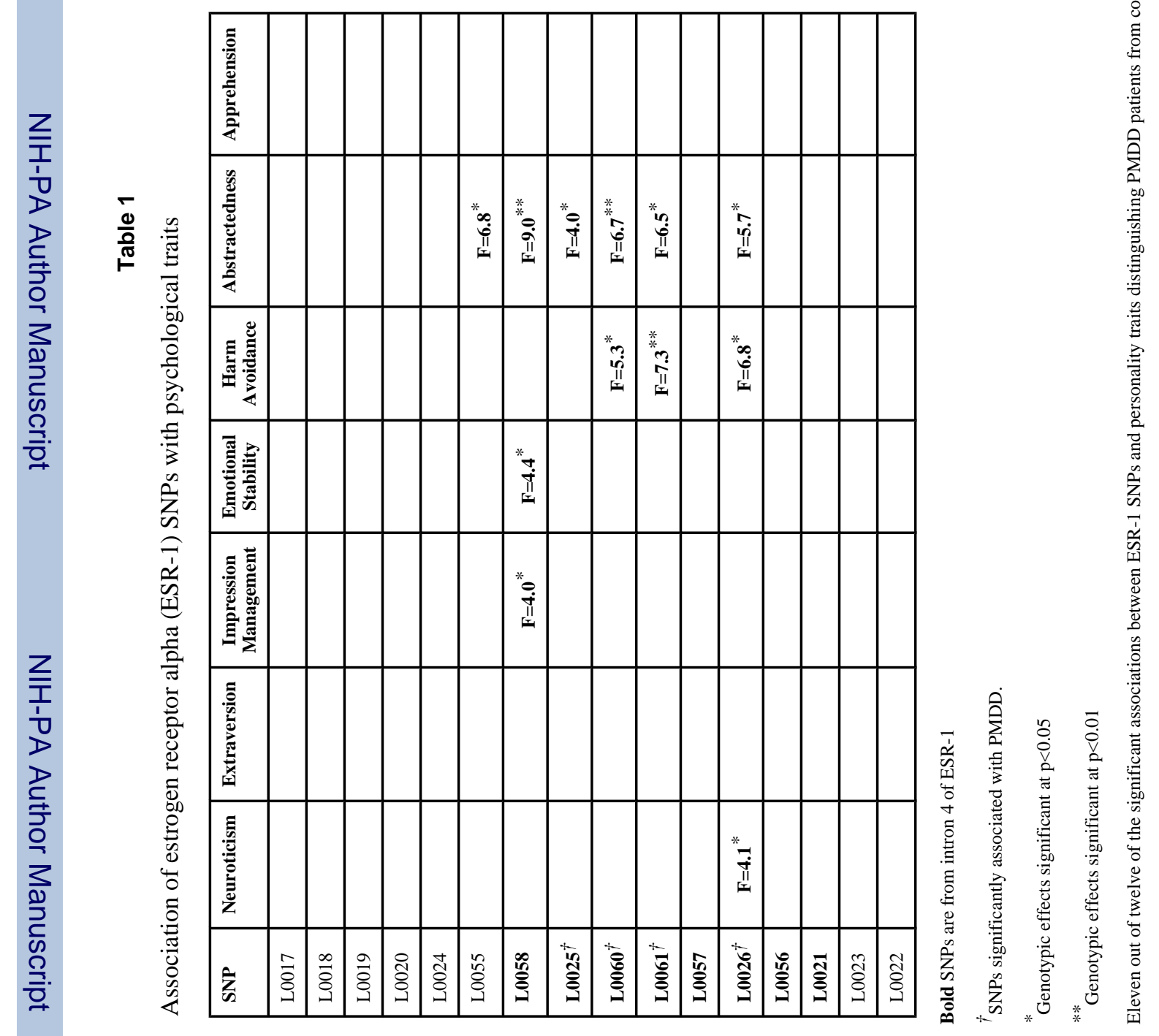

J Psychiatr Res. Author manuscript; available in PMC 2011 September 1. 